\title{
Perkembangan Kehidupan Sosial Kampung Kajang
}

\author{
Jumaisa \\ Ilmu Pendidikan Sosial, Fakultas Tarbiyah, IAIN Parepare \\ Email: jumaisa@iainpare.ac.id
}

\begin{abstract}
This study aims to describe the development of social life of Kampung Kajang in Makassar, South Sulawesi. This type of research is qualitative. As historical research, the methodology used is historical research methodology. The object of the research is Kampung Kajang located in Makassar. The development of social life in Kampung Kajang is quite good. The form of social interaction between the residents of Kampung Kajang and the other community is an associative interaction which has a sense of solidarity as a member of the community.
\end{abstract}

Keywords: Social Aspect, Kampung Kajang, History

Abstrak. Penelitian ini bertujuan untuk mengkaji perkembangan kehidupan sosial Kampung Kajang di Makassar Sulawesi Selatan. Jenis penelitian ini adalah kualitatif. Sebagai penelitian sejarah, maka metodologi yang digunakan adalah metodologi penelitian sejarah. Objek penelitian adalah Kampung Kajang yang berada di Makassar. Perkembangan kehidupan sosial Kampung Kajang cukup baik. Bentuk interaksi sosial antara warga Kampung Kajang dengan masyarakat lainnya adalah interaksi asosiatif yang mana memiliki rasa solidaritas sebagai anggota masyarakat.

Kata Kunci: Aspek Sosial, Kampung Kajang, Sejarah

\section{PENDAHULUAN}

Nama Kampung Kajang merupakan sebuah nama kampung yang diberi oleh masyarakat yang bertempat tinggal di Kelurahan Tamangapa, Kecamatan Manggala di Makassar Sulawesi Selatan. Karena keluarga yang pertama kali tinggal di daerah tersebut merupakan keluarga Almarhum Puang Ambo (Dg. Rapi) dengan isterinya Almarhuma Sitti Saindah Adaizzati, yang mana asal daerah Almarhum Puang Ambo ini adalah dari Bone dan istrinya Almarhuma Siti Saindah Addaizzati ini adalah orang Kajang, masyarakat yang ada di Kelurahan Tamanggapa menyebutnya sebagai "Bone $\mathrm{Na}$ To Kajang" yang mempunyai arti dalam bahasa Konjo adalah "Isinya Orang Kajang". Oleh sebab itu, masyarakat Kelurahan Tamangapa, Kecamatan Manggala memberi nama kampung tersebut Kampung Kajang.

Kampung Kajang terletak di wilayah Kelurahan Tamangapa, Kecamatan Manggala. Pada awalnya daerah ini hanya merupakan sebuah hutan dan rawa-rawa daerah ini dulunya merupakan jalur perampok dan pertama kalinya daerah ini hanya di huni oleh satu keluarga saja yakni keluarga Almarhum Puang Ambo (Dg.
Rapi) pada tahun 1995. Karena di kampung ini lebih banyak dihuni oleh orang Kajang yang mana mereka masih memegang teguh prinsip kekeluargaan, kebersamaan, dan gotong royong yang masih kuat serta masih memperhatikan tradisi daerahnya walaupun berada di daerah orang lain seperti adat pernikahan (adat pa'buntinggang) dan pesta adat Akkalomba. Selain itu, di daerah ini juga merupakan satusatunya daerah terluas di Kelurahan Tamangapa dan jumlah penduduknya terus bertambah dari tahun ke tahun. Alasan inilah yang menjadi pembeda dengan kampung lainnya yang ada di Makassar, sehingga studi terkait Kampung Kajang perlu dilakukan.

Tujuan penelitian ini adalah untuk mengkaji perkembangan atas kehidupan sosial di Kampung Kajang sehingga menyediakan gambaran umum mengenai Kampung Kajang pada aspek sosial

\section{METODE}

Jenis penelitian ini ialah kualitatif. Metode penelitian ini bersifat deskriptif analitis dengan tujuan untuk menemukan dan mendeskripsikan secara analitis serta 
menginterpretasikan hal-hal yang terkait dengan Perkampungan Kajang (1995-2015).

Sebagai penelitian sejarah, maka metodologi yang digunakan adalah metodologi penelitian sejarah. Metode sejarah merupakan cara atau teknik dalam merekonstruksi peristiwa masa lampau, melalui empat tahapan kerja yaitu heuristik (pengumpulan sumber), kritik sumber (eksternal/bahan dan internal/isi), interpretasi (penafsiran), dan historiografi (penulisan sejarah) (Madjid dan Hamid, 2008).

Penelitian ini mengambil lokasi di Kampung Kajang, RT4 RW4 Kelurahan Tamangapa Kecamatan Manggala, Kotamadya Makassar. Kecamatan Manggala merupakan salah satu dari 14 Kecamatan di Kota Makassar yang berbatasan dengan Kecamatan Tamalanrea di Sebelah Utara, Kabupaten Maros di Sebelah Timur, Kabupaten Gowa di Sebelah Selatan, dan Kecamatan Panakukang di Sebelah Barat. Kecamatan Manggala ini terdiri dari 6 Kelurahan dengan luas wilayah $24,14 \mathrm{~km}^{2}$ (Badan Pusat Statistik, 2015). Kampung Kajang ini terdapat di Kelurahan Tamangapa, dapat dicapai dengan menggunakan jalur darat.

Wawancara dilakukan dengan masyarakat Kampung Kajang dan masyarakat Kelurahan Tamangapa yang ada di Kota Makassar. Observasi dilakukan dengan cara melihat langsung bagaimana kegiatan masyarakat Kampung Kajang. Penelusuran bahan pustaka dilakukan pada berbagai perpustakaan.

\section{HASIL DAN PEMBAHASAN}

Perkembangan bidang sosial adalah aspekaspek perubahan yang biasa dikehendaki oleh warga kota lebih ke pemenuhan kebutuhankebutuhan dan prasarana fasilitas hidup dalam kota, terutama bertambahnya penduduk di kota baik secara alamiah maupun migrasi atau suatu perpindahan, menyebabkan semakin besarnya fasilitas-fasilitas yang dibutuhkan, seperti ruang dan prasarana (rumah, jalan, air minum, dan sebagainya). Meskipun demikian tidak semua kota berkembang sama cepatnya. a) letak suatu kota, b) iklim dan relief, c) sumber alam, d) tanah, e)demografi dan kesehatan, f) pendidikan dan kebudayaan, g) teknologi dan elektrifikasi, h) transport dan lalu lintas (Kaharuddin, 1992).
Kedatangan orang Kajang ke Makassar rata-rata berasal dari masyarakat Kajang kawasan luar. Secara geografis masyarakat adat Amma Toa terbagi atas Kawasan Dalam (Tana Kekea) dan Kawasan Luar (Tana Lohea). Masyarakat kawasan dalam tersebar di beberapa desa antara lain Desa Tana Toa, Bonto Baji, Malelleng, Pattiroang, Batu Nilamung dan bagian wilayah Desa Tambangan. Kawasan masyarakat Adat Kawasan Dalam secara keseluruhan berbatasan dengan tuli di sebelah utara, dengan Limbah sebelah timur dengan Seppa di sebelah selatan dan dengan Doro di sebelah Barat. Sedangkan Kawasan Luar tersebar di hampir seluruh Kecamatan Kajang dan beberapa desa di wilayah kecamatan Bulukumba, di antaranya di Desa Jojjolo, Desa Tibona, Desa Bino, Minasa, dan Desa Batu Lohe (Palammai dan Mappasomba, 2012).

Masyarakat yang bertempat tinggal di Kawasan Dalam itu masih kuat melestarikan warisan leluhurnya, mereka masih berpegang teguh pada ajaran dan adat Ammatoa, mereka mempraktikkan cara hidup yang sangat sederhana, dan mereka berkeyakinan bahwa pengaruh teknologi sangat buruk kepada manusia. Oleh karena itu, mereka menolak segala sesuatu yang berbau teknologi karena dianggap dapat merusak lingkungan dan alam semesta. Sedangkan masyarakat yang bertempat tinggal di Kawasan Luar telah mengalami perubahan sesuai dengan tuntutan zaman (Darmapoetra, 2014).

Kampung kota adalah suatu bentuk pemukiman di wilayah perkotaan yang khas Indonesia dengan penduduk masih membawa sifat dan perilaku kehidupan pedesaan yang terjalin dalam ikatan kekeluargaan yang erat. Pertambahan ruang secara vertikal cenderung akan menjadi cara untuk terus meningkatkan fungsi-fungsi hunian yang semakin kompleks khususnya di daerah kampung-kampung perkotaan. Seperti kampung Kajang yang berada di RT4 RW4 Kelurahan Tamangapa Kecamatan Manggala Kota Makassar ini.

Dalam masalah pembahasan perubahan sosial budaya di Kampung Kajang ini yang mana struktur sosial meliputi berbagai komponen atau unsur-unsur pokok hal tersebut sesuai dengan pernyataan Soleman B. Taneko yang 
menyatakan bahwa struktur sosial adalah merupakan jalinan antara unsur-unsur sosial yang pokok itu yaitu kaidah-kaidah atau normanorma sosial, lembaga-lembaga sosial, kelompok-kelompok sosial serta lapisan-lapisan sosial. Dalam tahap struktur sosial yaitu bagaimana interpretasikan oleh Raymond Firth, sebagai suatu pergaulan hidup manusia meliputi berbagai tipe kelompok yang terjadi dari banyak orang dan meliputi pula lembaga-lembaga didalamnya yang mana orang banyak ambil bagian (1960-106) (Faisal, dkk., 1999).

Sistem sosial dan budaya antar komunitas yang mendiami Kampung Kajang, dalam konteks demografis, masyarakat Kampung Kajang yang dilatar belakangi oleh beberapa komunitas dari kelompok etnik sehingga mendeskripsikan komunitas yang multi ragam etnik. Kedatangan orang dari daerah lain seperti orang Malino, Jawa, Bone, Jeneponto, Sinjai, Flores dan dominan orang dari Kajang kabupaten Bulukumba, sehingga diwarnai dan membentuk suatu komunitas yang membentuk masyarakat multi ras mewujudkan berbagai sistem nilai, tradisi, dan berbagai aspek kehidupan sosial budaya. Kondisi sosial budaya seperti ini berpeluang untuk terjadinya konflik SARA (Suku, Ras, Agama).

Di Kampung Kajang ini terdapat banyak aspek yang dapat kita munculkan untuk kita berikan batasan tentang bagaimana kita mengkaji tentang masalah perubahan sosial budaya, khususnya di Kampung Kajang. Kampung Kajang ini merupakan suatu pemukiman yang berada di Kelurahan Tamangapa, Kecamatan Manggala, Kota Makassar. Secara administratif, Kelurahan Tamangapa memiliki luas $662 \mathrm{~km}^{2}$. Ini sudah termasuk ini sudah termasuk Kampung Kajang dengan luas sekitar $40.649 \mathrm{~m}^{3}$. Kampung Kajang ini berada di RW 4 RT 4 dari total 7 RW dan 34 RT di Kelurahan Tamangapa ini. Jumlah penduduk Kampung Kajang di RT 4 yaitu 537 jiwa dari total penduduk Kelurahan Tamangapa \pm 11.365 jiwa. Mayoritas penduduk Kampung Kajang ini adalah orang yang berasal dari Kajang Kabupaten Bulukumba sebanyak 90\% sisanya adalah suku bugis, suku makassar, beserta beberapa pendatang dari Toraja, Flores, dan Jawa yang bermukim di Kampung Kajang ini. Ciri Khas Kampung Kajang ini adalah mempertahankan tardisi leluhurnya seperti mengadakan pesta adat Akkalomba, beberapa aturan dalam pesta pernikahan, memegang teguh prinsip kekeluargaan dan tidak mengenal malu selama yang dikerjakan masih halal serta mempunyai semangat gotong royong yang tinggi.

Untuk menemukan Kampung Kajang yang terletak di Kelurahan Tamangapa, Kecamatan Manggala ini amat mudah, karena Kampung Kajang ini berada di Jalan Poros Tamangapa. Jika dari Kelurahan Bangkala Kampung Kajang ini berada di sebelah kiri sedangkan jika dari Kelurahan Manggala atau dari Kecamatan somba Opu kampung Kajang ini berada di sebelah kanan poros Tamangapa.

Ibu-ibu rumah tangga yang berada di Kampung Kajang ini mempunyai beberapa kegiatan-kegiatan sosial diantaranya : pengajian yang diadakan oleh ibu-ibu setiap hari selasa, dan keterampilan daur ulang sampah bekas, dan ikut dalam kegiatan peduli sampah yang disebut sebagai BANK sampah. Kegiatan ini disebut dengan Bank Sampah dan hampir 99 \% ibu-ibu terlibat dalam kegiatan tersebut. Sebagaimana yang di utarakan oleh Nurlia Lipsa saat wawancara pada tanggal 5 April 2016 yaitu:

Pekerjaan ibu-ibu disini itu, bukan cuman membersihkan rumah, menyiapkan makanan, dan mengurus anak-anak. Tetapi, ibu-ibu disini itu bikin kegiatan kegiatan sosial kaya pengajian dan keterampilan daur ulang sampah. Sampah-sampah yang sudah dibuang, dipilih kembali yang masih bisa digunakan seperti itu botol-botol aqua, tempat teh gelas, dan masih banyak yang lain. Kalau sudah dipilih sampah yang masih bisa di daur ulang itu mi di timbang sehingga bisa juga menghasilkan uang dan hampir 99\% ibu-ibu disini ikut kegiatan ini. Prinsipnya ibu-ibu juga disini itu tidak kenal malu yang penting halal.

Kegiatan keagamaan seperti pengajian ini dilakukan setiap bulan yang mana kegiatan ini ada yang diselenggarakan oleh pihak kecamatan dan ada juga yang diselanggarakan oleh Majelis Ta'lim Assyfa Kampung Kajang. Kegiatan keagamaan yang diadakan oleh pihak kecamatan ini dilakukan sebanyak dua kali dalam sebulan yakni dilakukan pada hari selasa minggu pertama 
dengan kegiatan pengajian dan hari selasa minggu ketiga itu ceramah agama. Kegiatan pengajian dan ceramah agama ini dilakukan setiap selesai sholat ashar sampai selesai, pada kegiatan minggu ketiga yang diadakan oleh kecamatan ini menghadirkan penceramah. Seperti pada minggu ketiga bulan Maret tanggal 15 pukul 16.00 sampai selesai, penceramahnya pada saat itu adalah Ustad Hammad dengan materi ceramah tentang Akidah dan tata cara mensucikan diri yang benar atau tentang junub, dan dihadiri oleh 25 ibu-ibu Kampung Kajang pada saat itu. Sedangkan kegiatan keagamaan yang dilakukan setiap tanggal 4 minggu pertama dan setiap hari selasa minggu kedua dan minggu keempat setiap bulan itu diselenggarakan oleh Majelis Ta'lim Assyfa dengan dibantu oleh komunitas perempuan pencinta Al-qur'an yang mempunyai sekretariat di Masjid Raya Baruga. Kegiatan keagamaan ini dihadiri oleh ibu-ibu yang berada di Kampung Kajang. Pengajian ibuibu yang ada di Kampung Kajang ini baik yang diselanggarakan oleh pihak kecamatan maupun yang di selenggarakan Majelis Ta'lim Assyfa sangat berdampak positif bagi ibu-ibu yang berada di Kampung Kajang karena ibu-ibu yang dulunya tidak tahu mengaji menjadi tahu setelah ikut pengajian.

Kegiatan daur ulang sampah atau mengelola sampah bekas untuk menghasilkan sebuah benda kerajinan tangan awalnya hanya dilakukan pelatihan di Kantor Kecamatan saja yang diikuti oleh perwakilan warga setiap kelurahan yang ada di Kecamatan Manggala. Dalam kegiatan ini ada dua tipe orang yang ikut yakni ada yang mengikuti kegiatan ini karena alasan benar-benar ingin mendapatkan keterampilan dalam mengelolah sampah bekas dan ada juga yang mengikuti kegiatan ini karena hanya ingin mendapatkan amplop saja karena kegiatan ini mempunyai dana dari pemerintah. Namun, karena waktu yang sangat singkat dalam mengikuti kegiatan ini membuat ibu-ibu di Kampung Kajang yang ingin lebih mendalami kegiatan tersebut dan ingin memiliki keterampilan ini membentuk sebuah perkumpulan untuk belajar lebih dalam mengenai kegiatan daur ulang sampah ini agar dapat menghasilkan sebuah kerajinan tangan. Kegiatan ini dilanjutkan di rumah Ibu Nurlia dan sekarang kegiatan ini menjadi kegiatan rutinitas ibu-ibu di Kampung Kajang yang dilakukan setiap hari minggu. Kegiatan ini menghasilkan benda-benda kerajinan tangan seperti bungabunga untuk hiasan diruang tamu. Kegiatan ini diikuti oleh ibu-ibu di Kampung Kajang sekitar $80 \%$. Kegiatan keterampilan daur ulang sampah ini dominan diikuti oleh ibu-ibu seperti Ibu Nurlia, Ibu Ramlah, Ibu Rosmi, Ibu Asmi, Ibu Nur Ismi, Ibu Sri Wahyuni, Ibu Darma, Ibu Nani dan lain-lain.

Selain kegiatan daur ulang sampah bekas untuk menjadi sebuah benda hasil kerajinan tangan ada juga kegiatan yang di sebut Bank Sampah. Bank sampah ini merupakan suatu kegiatan yang diadakan oleh Pak Walikota untuk peduli terhadap sampah. Bank sampah yang dibentuk di Kampung Kajang merupakan perkumpulan yang dibentuk oleh warga Kampung Kajang yang mana dalam perkumpulan itu warga yang ikut diberikan modal sebesar Rp. 500.000/orang, kegiatan yang dilakukan dalam perkumpulan ini yaitu mengumpulkan sampah yang masih bisa digunakan kembali kemudian ditimbang setiap minggu namun pembayarannya tiap bulan ke rekening Bank Sampah nasabah yang ikut. Namun ada jadwal untuk pencairan dana yakni dilakukan setiap hari senin hanya dua kali sebulan.

Jika nasabah Bank Sampah ini ingin mengambil uangnya untuk keperluan di rumahnya itu dapat mengabil uangnya pada waktu jadwal pencairan dana yang sudah ditetapkan setiap bulan. Dalam pembayarannya, warga di berikan pilihan dibayar menggunakan uang, beras, minyak goreng atau sejenisnya sesuai dengan harga yang akan diberikan dari hasil sampah yang sudah di timbang dan di simpan di Bank Sampah tersebut. Kegiatan ini diikuti oleh Bapak-bapak dan Ibu-ibu yang ada di Kampung Kajang. Namun, yang lebih dominan ikut itu adalah ibu-ibu. Mereka yang ikut itu adalah mereka yang berpartisipasi pada kegiatan keterampilan daur ulang sampah.

Dalam kaitannya dengan norma-norma dan nilai-nilai sosial yang berlaku dalam masyarakat terhadap adanya kesinambungan karena adanya penyesuaian diri terhadap masyarakat yang didatanginya. Bahkan kecenderungan 
terwujudnya suatu interaksi dan integrasi sosial semakin tampak, hal ini dapat dilihat secara nyata dengan adanya kawin mawin antara orang Kajang dengan penduduk setempat yang dapat memperlancar proses asimilasi dan akulturasi kedua suku tersebut.

Adapun mengenai tanggapan/sikap masyarakat Kelurahan Tamangapa terhadap kehadiran orang Kajang di Kelurahannya adalah "positif", hal ini dapat dilihat dengan kehadiran orang Kajang menetap dan membentuk perkampungan di Kelurahannya. Mereka menerimanya dengan baik dan tidak keberatan sama sekali selama orang Kajang di Bulukumba tidak ada yang keberatan dengan adanya perkampungan Kajang di Makassar. Hal ini dapat di ketahui melalui penjelasan $\mathrm{H}$. Basir pada waktu wawancara di rumahnya di Kelurahan Tamangapa sebagai berikut:

Kedatangan orang Kajang di Kelurahan Tamangapa itu seperti pembawa rahmat dan berkah tersendiri. Mengapa saya katakan seperti itu, karena dengan kedatangan orang Kajang di Kelurahan Tamangapa ini daerah yang dulunya kumuh bisa berubah dan tertatah menjadi lebih baik. Mereka juga mempunyai sikap kegotong royong dan solidaritas yang sangat tinggi, warganya ramah dan disana tidak itu aman-aman saja. Mengenai mereka membuat perkampungan di Kelurahan Tamangapa saya pribadi tidak ada masalah selama orang di Kajang Kabupaten Bulukumba tidak ada yang keberatan dan protes kalau di Makassar tepatnya di Kelurahan Tamangapa ini ada Kampung Kajang.

Penjelasan diatas dapat menunjukkan bahwa tanggapan/sikap masyarakat Kelurahan Tamangapa dengan adanya Kampung Kajang itu sangat positif dan diterima dengan baik. Warga Kampung Kajang sendiri dalam pergaulan sehari-harinya umumnya itu bersikap ramah. Hal ini memberikan keterangan bahwa dalam pergaulan antara kedua belah pihak harus saling menghormati satu sama lain.

\section{KESIMPULAN}

Perkembangan kehidupan sosial Kampung Kajang terbilang cukup baik. Dalam pergaulan sehari-hari mereka menggunakan Bahasa Konjo, Bahasa Makassar, Bahasa Bugis, dan Bahasa Indonesia.

Bentuk interaksi sosial antara warga Kampung Kajang dengan masyarakat Kelurahan Tamangapa adalah interaksi asosiatif yang mana kedua belah pihak mempunyai kecenderungan meningkatkan rasa solidaritas sebagai anggota masyarakat. Hal ini dapat diamati dalam bentuk kerja sama warga Kampung Kajang dengan warga yang ada di Kelurahan Tamangapa.

\section{SARAN}

Meski tergolong sebagai kelompok minoritas dan berstatus sebagai warga pendatang yang memiliki perbedaan bahasa maupun kebiasaan hidup dengan penduduk yang ada di Kelurahan Tamangapa, namun diharapkan interaksi yang telah terbangun sejak lama tetap dijaga agar kehidupan sebagai penduduk Kelurahan Tamangapa tetap berlangsung harmonis.

\section{DAFTAR PUSTAKA}

Badan Pusat Statistik. (2015). Kecamatan Manggala Dalam Angka 2015. Makassar: Badan Pusat Statistik.

Darmapoetra, J. (2014). Kajang Pencipta Kebersamaan dan Pelestari Alam. Makassar: Arus Timur.

Faisal, Muh. Alimuddin, dan Drs. Ahmad Yusuf. (1999). Lingkungan Budaya Pada Masyarakat Kompleks Perumahan Rakyat Daerah Sulawesi Selatan. Makassar

Kaharuddin H. (1992). Pembangunan Masyarakat. Yogyakarta: Liberty.

Madjid, Muhammad Saleh dan Hamid, Abdul Rahman. (2008). Pengantar Ilmu Sejarah. Makassar : Rayhan Intermedia.

Palammai, Ramli dan Mappasomba, Andika. (2012). Sejarah Eksistensi Ada' Lima Karaeng Tallua di Kajang. (Bulukumba: Dinas Kebudayaan dan Pariwisata Kabupaten Bulukumba. 